\title{
The impact of body mass index on dosimetric quality in low-dose-rate prostate brachytherapy
}

\author{
Michelle I. Echevarria, MD!, Arash O. Naghavi, MS, MD', Puja S. Venkat, MD', Yazan A. Abuodeh, MD', Carlos Chevere, MD², \\ Kosj Yamoah, MD, PhD' \\ IRadiation Oncology, H. Lee Moffitt Cancer Center and Research Institute, Tampa, FL, USA, ²Radiation Oncology, Hospital Oncológico, HIMA \\ San Pablo, Caguas, Portorico
}

\begin{abstract}
Purpose: Low-dose-rate (LDR) brachytherapy has been established as an effective and safe treatment option for men with low and intermediate risk prostate cancer. In this retrospective analysis, we sought to study the effect of body mass index (BMI) on post-implant dosimetric quality.

Material and methods: After institutional approval, records of patients with non-metastatic prostate cancer treated in Puerto Rico with LDR brachytherapy during 2008-2013 were reviewed. All patients were implanted with ${ }^{125} \mathrm{I}$ seeds to a prescription dose of 145 Gy. Computed tomography (CT) based dosimetry was performed 1 month after implant. Patients with at least 1 year of prostate-specific antigen (PSA) follow-up were included. Factors predictive of adequate $\mathrm{D}_{90}$ coverage $\left(\geq 140 \mathrm{~Gy}\right.$ ) were compared via the Pearson $\chi^{2}$ or Wilcoxon rank-sum test as appropriate.

Results: One-hundred and four patients were included in this study, with $53(51 \%)$ patients having a $\mathrm{D}_{90} \geq 140 \mathrm{~Gy}$. The only factor associated with a dosimetric coverage detriment $\left(D_{90}<140 \mathrm{~Gy}\right)$ was BMI $\geq 25 \mathrm{~kg} / \mathrm{m}^{2}(p=0.03)$. Prostate volume $(p=0.26)$, initial PSA $(p=0.236)$, age $(p=0.49)$, hormone use $(p=0.93)$, percent of cores positive $(p=0.95)$, risk group $(p=0.24)$, tumor stage $(p=0.66)$, and Gleason score $(p=0.61)$ did not predict $\mathrm{D}_{90}$.

Conclusions: In this study we show that BMI is a significant pre-implant predictor of $\mathrm{D}_{90}(<140$ Gy vs. $\geq 140 \mathrm{~Gy}$ ). Although other studies have reported that prostate volume also affects $\mathrm{D}_{90}$, our study did not find this correlation to be statistically significant, likely because all of our patients had a prostate volume $<50 \mathrm{cc}$. Our study suggests that in patients with higher BMI values, more rigorous peri-implant dosimetric parameters may need to be applied in order to achieve a target $\mathrm{D}_{90}>140 \mathrm{~Gy}$.
\end{abstract}

Key words: BMI, low-dose-rate brachytherapy, prostate cancer, seeds.

\section{Purpose}

Prostate cancer is known to be the leading cause of malignancy and the second leading cause of cancer-related death among men. In 2015 alone, approximately 220,800 men were diagnosed with prostate cancer in the United States, making up about one-quarter of new cancer diagnoses [1]. Various epidemiologic studies have found a correlation between obesity and an increased risk of certain cancers [2,3]. In addition, it has been reported that obese men have a greater risk of prostate cancer-related death [3]. Based on body mass index (BMI), an indicator of obesity, more than 1 in 3 adults in the United States are considered obese. Obesity has been associated with an increased risk of biochemical failure after treatment for prostate cancer [4]. In addition to its association with biochemical failure after treatment, studies have also found an association between increased BMI and an advanced prostate tumor stage [5]. Furthermore, in a recently pub- lished study, patients with an elevated BMI were found to have a higher rate of adverse pathologic features such as extraprostatic extension and positive surgical margins [6]. With the high prevalence of both prostate cancer and obesity, the importance of adjusting current treatment modalities for obese patients with prostate cancer has become crucial for achieving long-term biochemical control in this cohort of patients.

Current treatment techniques for prostate cancer include radical prostatectomy, external beam radiation therapy, and brachytherapy. Among these treatment modalities, low-dose-rate (LDR) brachytherapy has been established as an effective and safe treatment option for men with low and intermediate risk prostate cancer. The dose delivered to $90 \%$ of the prostate volume, or $\mathrm{D}_{90}$, which is obtained through a computed tomography (CT) based post-implant dosimetric analysis, has been used as a measure of implant quality and has been found to be
Address for correspondence: Kosj Yamoah, MD, PhD, Radiation Oncology, H. Lee Moffitt Cancer Center and Research Institute, 12902 Magnolia Drive, Tampa, FL 33612, USA, phone: +1 813-745-3053, fax: +1 813-745-7231, $\bowtie$ e-mail: Kosj.Yamoah@moffitt.org
Received: 09.08 .2016

Accepted: 19.10 .2016

Published: 31.10.2016 
a strong predictor of outcome among men treated with LDR brachytherapy [7]. Although a $\mathrm{D}_{90}>130 \mathrm{~Gy}$ is considered adequate by the American Brachytherapy Society [8], various studies have shown that a $D_{90} \geq 140$ Gy is associated with improved biochemical control $[9,10]$. Previous studies have found that specific factors such as prostate volume, post-implant prostatic edema, and the number of seeds implanted can influence $D_{90}[11,12,13]$.

Identifying factors that lead to suboptimal dosimetric outcomes are important in order to improve implant quality as well as clinical outcomes. In this retrospective analysis, we sought to study the effect of BMI on postimplant dosimetric quality, specifically $\mathrm{D}_{90}$.

\section{Material and methods}

\section{Patients}

After institutional approval, records of patients with non-metastatic prostate cancer treated in Puerto Rico with LDR brachytherapy during 2008-2013 were reviewed. Data from 104 Hispanic prostate cancer patients treated with LDR brachytherapy as monotherapy were analyzed retrospectively. All patients were implanted with ${ }^{125}$ I seeds to a prescription dose of $145 \mathrm{~Gy}$ to the prostate with a 3-5 mm margin. The BMI for all patients was calculated based on their weight prior to seed implantation at the time of pre-planning transrectal ultrasonography (TRUS). Hormonal therapy was used 3 months prior to pre-planning TRUS for cytoreduction purposes only for those patients with an initial prostate volume $>50 \mathrm{cc}$.

\section{Treatment planning}

A pre-planning technique was used with prostate mapping performed 2-4 weeks prior to seed implantation by TRUS [14]. Ultrasound images were acquired with patients in the extended lithotomy position. All treatment planning was conducted on the Panther Brachy Treatment Planning System (Prowess Inc., Concord, CA, USA). ${ }^{125}$ I loose seeds with a dose rate constant of 0.981 cGy/h/U (IsoAid Advantage, Port Richie, FL, USA) were placed transperineally under TRUS $5 \mathrm{~mm}$ apart from each other [15]. The seed implantation procedure was performed under epidural anesthesia with the patient in the extended lithotomy position lying in the same gurney as in the pre-planning TRUS. Dosimetric goals were as follows: $\mathrm{V}_{100}>95 \%, \mathrm{~V}_{150} \leq 50 \%$, and $\mathrm{D}_{90}>100 \%$ of the prescription dose. Computed tomography based dosimetry was performed 1 month after implant and was used to determine $D_{90}$, defined as the dose received by $90 \%$ of the prostate. All CT-based contours were performed, reviewed, and approved by the same experienced radiation oncologist. Patients with at least 1 year of PSA follow-up were included.

\section{Statistical methods}

Factors associated with adequate $D_{90}$ coverage $\left(D_{90}\right.$ $\geq 140$ Gy vs. $D_{90}<140$ Gy) were determined by the Pearson $\chi^{2}$ or Wilcoxon rank-sum test as appropriate. The factors evaluated for adequate $D_{90}$ coverage include pros- tate volume $(\mathrm{cc})$, BMI $\left(\mathrm{kg} / \mathrm{m}^{2}\right)$, initial PSA $(\mathrm{ng} / \mathrm{ml})$, age (years), hormone use, percent of cores positive, NCCN risk group (low vs. intermediate vs. high vs. unknown), tumor stage, and Gleason score (GS). A receiver operating characteristic (ROC) analysis was used to determine optimal predictive cut-off points for linear variables associated with $\mathrm{D}_{90}$ on univariate analysis (UVA).

Biochemical failure was defined based on the Phoenix definition (ASTRO consensus statement) [16], which is a rise in PSA $\geq 2 \mathrm{ng} / \mathrm{ml}$ above the nadir following treatment. Number of biochemical failures was compared via Pearson $\chi^{2}$. Freedom from biochemical failure (FFBF) is defined as time from implant to date of biochemical failure or last follow-up. Freedom from biochemical failure distribution was estimated using the Kaplan-Meier method and was compared via a log-rank test. Two-sided $p$-values and the level of significance of 0.05 were used for statistical analyses. All analyses were performed using SPSS version 22 (IBM, Armonk, NY, USA).

\section{Results \\ Patient characteristics}

The median follow-up of this study is 33 months (14 to 64 months). There were a total of 104 patients overall, of which $53(51 \%)$ patients have a $\mathrm{D}_{90} \geq 140 \mathrm{~Gy}$. The majority of the patients were GS $6(n=90,87 \%)$ with a median initial PSA of $4.7 \mathrm{ng} / \mathrm{ml}$. The median age was 66 years, with a median prostate volume of $29 \mathrm{cc}$ (Table 1 ).

\section{Predictors of adequate dose coverage}

The factors associated with $\mathrm{D}_{90}(<140 \mathrm{~Gy}$ vs. $\geq 140 \mathrm{~Gy}$ ) are illustrated in Table 2 . The only factor associated with inadequate $\mathrm{D}_{90}$ coverage ( $<140 \mathrm{~Gy}$ ) was higher BMI (median: 28.3 vs. $\left.26.7 \mathrm{~kg} / \mathrm{m}^{2}, p=0.023\right)$. Prostate volume $(p=0.26)$, initial PSA $(p=0.236)$, age $(p=0.49)$, hormone use $(p=0.93)$, percent of cores positive $(p=0.95)$, NCCN risk group $(p=0.24)$, tumor stage $(p=0.66)$, and Gleason score $(p=0.61)$ were not associated with $\mathrm{D}_{90}$.

\section{Biochemical failure}

There were a total of $6(5.8 \%)$ biochemical failures in this study, with a 5-year freedom from biochemical failure of $90.8 \%$ (Figure 1 ). $\mathrm{D}_{90} \geq 140$ Gy was not associated with a significant difference in biochemical failure $(7.5 \%$ vs. $3.9 \%, \chi^{2} p=0.43$ ) or 5-year freedom from biochemical failure (90\% vs. $91.3 \%, \log$-rank $p=0.53)$, when compared to $\mathrm{D}_{90}<140 \mathrm{~Gy}$. Categorical BMI showed that overweight $\left(\mathrm{BMI} \geq 25 \mathrm{~kg} / \mathrm{m}^{2}\right)$ and obesity $\left(\mathrm{BMI} \geq 30 \mathrm{~kg} / \mathrm{m}^{2}\right.$ ) were not associated with 5-year freedom from biochemical failure $(p=0.19$ and $p=0.95)$.

\section{Discussion}

The management of prostate cancer comprises a broad spectrum of treatment modalities. Prostate brachytherapy, specifically LDR brachytherapy, has been used for many years as an effective and safe treatment option for low and intermediate risk prostate cancer patients. In our 
Table 1. Patient characteristics $(N=104)$

\begin{tabular}{|c|c|}
\hline Factor & Median (range) \\
\hline Age (years) & $66(52-84)$ \\
\hline BMI $\left(\mathrm{kg} / \mathrm{m}^{2}\right)$ & $27.2(18.1-48.4)$ \\
\hline Initial PSA (ng/ml) & $4.7(0.6-19.7)$ \\
\hline Prostate volume (cc) & $29(11-48)$ \\
\hline \multirow[t]{2}{*}{ Follow-up (months) } & $33(14-64)$ \\
\hline & $n(\%)$ \\
\hline \multicolumn{2}{|l|}{ BMI } \\
\hline$<25 \mathrm{~kg} / \mathrm{m}^{2}$ & $71(68)$ \\
\hline$\geq 25 \mathrm{~kg} / \mathrm{m}^{2}$ & $18(17)$ \\
\hline Unknown & $15(14)$ \\
\hline \multicolumn{2}{|l|}{ NCCN risk group } \\
\hline Low & $80(77)$ \\
\hline Intermediate & $21(20)$ \\
\hline High & $1(1)$ \\
\hline Unknown & $2(2)$ \\
\hline \multicolumn{2}{|l|}{ Tumor stage } \\
\hline T1c & $85(82)$ \\
\hline T2a & $8(8)$ \\
\hline $\mathrm{T} 2 \mathrm{~b}$ & $7(7)$ \\
\hline $\mathrm{T} 2 \mathrm{C}$ & $4(4)$ \\
\hline \multicolumn{2}{|l|}{ Gleason score } \\
\hline 5 & $6(6)$ \\
\hline 6 & $90(87)$ \\
\hline 7 & $7(7)$ \\
\hline$\geq 8$ & $1(1)$ \\
\hline \multicolumn{2}{|c|}{ Percent of cores positive } \\
\hline$<50 \%$ & $94(90)$ \\
\hline$\geq 50 \%$ & $10(10)$ \\
\hline Unknown & $0(0)$ \\
\hline \multicolumn{2}{|l|}{$\mathrm{D}_{90}(>140 \mathrm{~Gy})$} \\
\hline$<140$ Gy & $51(49)$ \\
\hline$\geq 140$ Gy & $53(51)$ \\
\hline \multicolumn{2}{|l|}{ Hormone therapy } \\
\hline No & $86(83)$ \\
\hline Yes & $18(17)$ \\
\hline \multicolumn{2}{|l|}{ Biochemical failure } \\
\hline No & $98(94)$ \\
\hline Yes & $6(6)$ \\
\hline
\end{tabular}

BMI - body mass index, PSA - prostate-specific antigen, NCCN - National Com prehensive Cancer Network, $D_{90}$ - the minimum dose received by $90 \%$ of the prostate volume
Table 2. Factors associated with adequate dosimetric coverage

\begin{tabular}{lccc} 
Characteristics & $<140$ Gy $(n=51)$ & $\geq 140$ Gy $(n=53)$ & UVA \\
\cline { 2 - 3 } & Median (range) & Median (range) & $(p)$ \\
\hline BMI (kg/m²) & $28.3(20.5-37.3)$ & $26.7(18.1-48.4)$ & 0.023 \\
\hline Age (years) & $66(52-84)$ & $66(53-80)$ & 0.487 \\
\hline $\begin{array}{l}\text { Prostate } \\
\text { volume (cc) }\end{array}$ & $30(14-45)$ & $26(11-48)$ & 0.261 \\
\hline $\begin{array}{l}\text { Initial PSA } \\
\text { (ng/ml) }\end{array}$ & $5.05(1.31-19.7)$ & $4.69(0.64-11.38)$ & 0.236 \\
\hline
\end{tabular}

\begin{tabular}{lccc}
\hline \multicolumn{1}{l}{$n(\%)$} & $n(\%)$ & \\
\hline NCCN risk group & & & \\
\hline Low & $36(71)$ & $44(83)$ & 0.241 \\
\hline Intermediate & $12(24)$ & $9(17)$ & \\
\hline High & $1(2)$ & $0 \%$ & \\
\hline Unknown & $2(4)$ & $0 \%$ & \\
\hline
\end{tabular}

\section{Tumor stage}

\begin{tabular}{lccc}
\hline T1c & $43(84)$ & $42(79)$ & 0.656 \\
\hline T2a & $3(6)$ & $5(9)$ & \\
\hline T2b & $4(8)$ & $3(6)$ & \\
\hline T2c & $1(2)$ & $3(6)$ &
\end{tabular}

Gleason score

\begin{tabular}{lccc}
\hline 5 & $2(4)$ & $4(8)$ & 0.611 \\
\hline 6 & $44(86)$ & $46(87)$ & \\
\hline 7 & $4(8)$ & $3(6)$ \\
\hline$\geq 8$ & $1(2)$ & $0(0)$
\end{tabular}

Percent of cores positive

\begin{tabular}{lccc}
\hline$<50 \%$ & $46(90)$ & $48(91)$ & 0.949 \\
\hline$\geq 50 \%$ & $5(10)$ & $5(9)$ & \\
\hline Hormone therapy & & & \\
\hline No & $42(82)$ & $44(83)$ & 0.928 \\
\hline Yes & $9(18)$ & $9(17)$ &
\end{tabular}

BMI - body mass index, PSA - prostate-specific antigen, NCCN - National Comprehensive Cancer Network, $D_{90}$ - the minimum dose received by $90 \%$ of the prostate volume

study we evaluated the effect of pre-implant factors on $D_{90}$ and chose a $D_{90} \geq 140 \mathrm{~Gy}$ as our cutoff point because various studies have shown better outcomes in patients treated with a $D_{90} \geq 140 \mathrm{~Gy}$. In a large single institution series of 1,298 patients, Henry and colleagues reported excellent biochemical control outcomes in low and intermediate risk patients treated with LDR brachytherapy, particularly those treated with a $D_{90} \geq 140$ Gy [9]. This study reported biochemical control of $88 \%$ in patients with a $\mathrm{D}_{90} \geq 140$ Gy vs. $78 \%$ in patients with a $\mathrm{D}_{90}<140 \mathrm{~Gy}$. 
Kollmeier et al. also described excellent biochemical control outcomes in patients with optimal dosimetry and reported a 94\% 8-year freedom from biochemical failure in patients with low-risk prostate cancer treated with a $\mathrm{D}_{90}$ $\geq 140$ Gy [10]. Studies like these not only established the effectiveness of LDR brachytherapy but also elucidated the importance of post-implant dosimetry and understanding the factors that can affect this. In addition to its effectiveness LDR brachytherapy is also associated with low morbidity. Given the commonly indolent nature of prostate cancer and the excellent outcomes among patients, the importance of using treatment modalities associated with low morbidity becomes crucial. Stock and colleagues found a low incidence of lower urinary tract symptoms in patients treated with LDR brachytherapy and reported that only $4 \%$ of these patients required a Foley catheter for $24-48$ hours post-implant and only $2 \%$ required a transurethral resection of the prostate [17]. Furthermore, they also reported that erectile function was not affected in the majority of patients.

Because dosimetric quality is strongly correlated with biochemical failure, various studies have looked at pre-implant factors that affect $D_{90}$. Although pre-implant planning is done using TRUS, after implantation CTbased images are used for dosimetric analysis. In a retrospective review of 210 patients, Sugawara et al. found the use of neoadjuvant hormonal therapy to be negatively associated with $\mathrm{D}_{90}$, whereas prostate volume and total radioactivity positively influenced post-implant $\mathrm{D}_{90}[18]$. In addition to prostate volume, prostatic edema, and the number of seeds implanted, Stock et al. found that CT/ US volume ratio had the greatest association with $\mathrm{D}_{90}$ and reported that patients with a greater CT/US ratio had a lower $\mathrm{D}_{90}[11]$.

In this study we analyzed the effect of BMI on post-implant dosimetric quality, specifically $\mathrm{D}_{90}$. Statistical analysis revealed that an increased BMI is a significant pre-implant factor which negatively affects $\mathrm{D}_{90}(<140 \mathrm{~Gy}$ vs. $\geq 140 \mathrm{~Gy}$ ). Although other studies have reported that prostate volume also affects $\mathrm{D}_{90}$, our study did not find this correlation to be statistically significant, likely because all of our patients had a prostate volume $<50 \mathrm{cc}$. Previous studies analyzing implant quality have reported a tendency for lower doses to be delivered anteriorly as compared to the posterior prostate in patients treated with LDR brachytherapy $[19,20]$. In a multi-institutional analysis of 4547 patients, Merrick et al. found that the $\mathrm{V}_{100}$ was less at the base $(51.5 \%)$ and anterior $(45.7 \%)$ of the gland when compared to the lateral $(68.8 \%)$, posterior $(75 \%)$, and mid gland $(65.9 \%)$ [21]. We postulate that increased perirectal and periprostatic fat in patients with higher BMI values may lead to difficulties accessing the anterior prostate, thereby resulting in an inferior $D_{90}$.

Other studies have found an association between BMI and rectal dosimetry, further illustrating the potential effect of adipose tissue in the prostate-rectum interface on dosimetric outcomes. A previous analysis of rectal dosimetry in 407 patients found that men with a higher BMI received a lower rectal wall dose as compared to those with a lower BMI [22]. Given that BMI is an indicator of adipose tissue, the authors came to the conclusion that

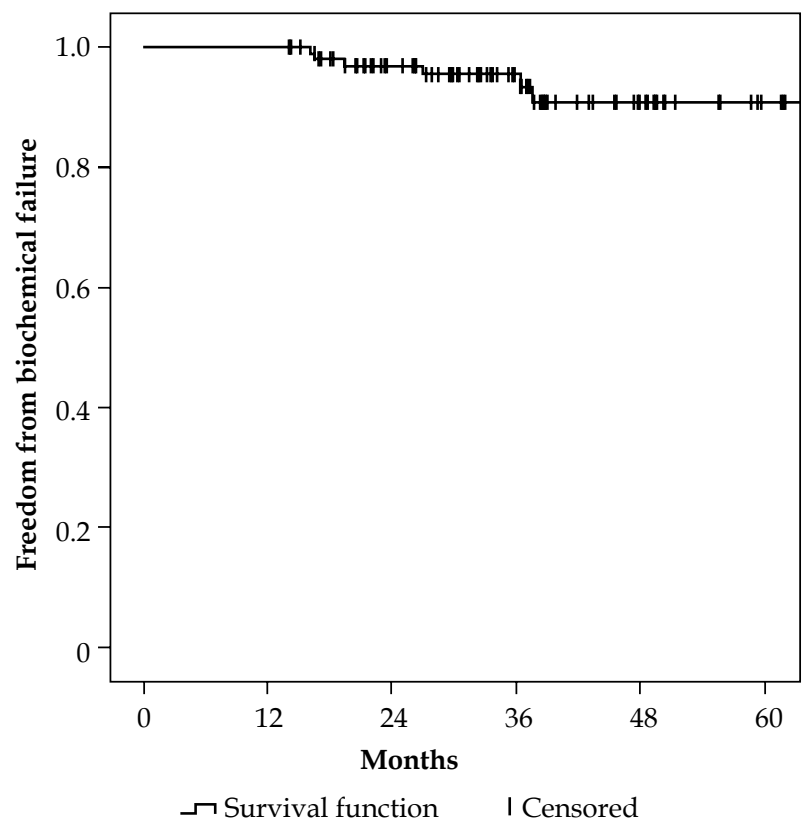

Fig. 1. Freedom from biochemical failure of the entire cohort

periprostatic fat could potentially decrease the dose received by the rectum. Tiberi et al. also found a negative correlation between BMI and dose to the rectum [23]. In addition to affecting rectal dose, we suggest that prostate-rectum interface adipose tissue can also have a negative effect on the anterior dose received by the prostate. In another study by Otón et al., rectal distention was found to negatively affect implant dosimetry, further illustrating the impact of peri-prostatic structures on implant quality [24].

Although in our cohort of patients there was no statistically significant difference in biochemical failure between patients treated with a $D_{90} \geq 140 \mathrm{~Gy}$ and those treated to a $\mathrm{D}_{90}<140 \mathrm{~Gy}$, we did not have an adequate patient volume to analyze this endpoint. Furthermore, the cohort of patients evaluated in this study had a limited follow-up time, which is very often seen in Puerto Rico, where the lack of physicians prevents adequate follow-up; and although a mean follow-up time of one year does not impact dosimetric quality, it may influence biochemical failure outcomes. Another limiting factor of this study is its retrospective nature and lack of dosimetric prostate sector analysis. While our results showed that BMI negatively affected dosimetric outcomes, a limitation of our study was the low number of patients included, specifically those with a BMI $\geq 25 \mathrm{~kg} / \mathrm{m}^{2}$. In this study, patient BMI was only obtained at the time of pre-planning TRUS, and because changes in BMI could potentially occur from the time of pre-planning to seed implantation, we were unable to evaluate whether these changes affected $D_{90}$. In the future, changes between pre-implant and post-implant BMI and the effect of these changes on dosimetric quality should be analyzed.

Now that we have shown an association between BMI and $D_{90}$, a future direction of this study would be to analyze the anterior prostatic dose in patients with a higher $\mathrm{BMI}$ and determine whether this is the cause of inferior 
dosimetric outcomes in this cohort of patients. Furthermore, other institutions have shown that the use of institution-specific nomograms can facilitate the implant planning process [25]. In addition to dosimetric parameters, patient characteristics such as BMI could also be used in such nomograms, which may result in higher quality of implantation.

\section{Conclusions}

Our results show that increased BMI is associated with inferior dosimetric outcomes, specifically $\mathrm{D}_{90}$. This data suggests that in order to achieve a $\mathrm{D}_{90} \geq 140 \mathrm{~Gy}$ in patients with higher $B M I$ values, $a D_{90}$ that is greater than the target post-implant $\mathrm{D}_{90}$ may need to be planned.

\section{Disclosure}

Authors report no conflict of interest.

\section{References}

1. Siegel RL, Miller KD, Jemal A. Cancer statistics, 2015. CA Cancer J Clin 2015; 65: 5-29.

2. Rapp K, Schroeder J, Klenk J et al. Obesity and incidence of cancer: a large cohort study of over 145,000 adults in Austria. Br J Cancer 2005; 93: 1062-1067.

3. Calle EE, Rodriguez C, Walker-Thurmond K et al. Overweight, obesity, and mortality from cancer in a prospectively studied cohort of U.S. adults. N Engl J Med 2003; 348: 16251638.

4. Freedland SJ, Aronson WJ, Kane CJ et al. Impact of obesity on biochemical control after radical prostatectomy for clinically localized prostate cancer: a report by the Shared Equal Access Regional Cancer Hospital database study group. J Clin Oncol 2004; 22: 446-453.

5. Spangler E, Zeigler-Johnson CM, Coomes M et al. Association of obesity with tumor characteristics and treatment failure of prostate cancer in African-American and European American men. J Urol 2007; 178: 1939-1944; discussion 1945.

6. Yamoah K, Zeigler-Johnson CM, Jeffers A et al. The impact of body mass index on treatment outcomes for patients with low-intermediate risk prostate cancer. BMC Cancer 2016; 16 : 557.

7. Stock RG, Stone N, Tabert A et al. A dose-response study for I-125 prostate implants. Int J Radiat Oncol Biol Phys 1998; 41: 101-108.

8. Davis BJ, Horwitz EM, Lee WR et al. American Brachytherapy Society consensus guidelines for transrectal ultrasound-guided permanent prostate brachytherapy. Brachytherapy 2012; 11: 6-19.

9. Henry AM, Al-Qaisieh B, Gould K et al. Outcomes following iodine-125 monotherapy for localized prostate cancer: the results of leeds 10-year single-center brachytherapy experience. Int J Radiat Oncol Biol Phys 2010; 76: 50-56.

10. Kollmeier MA, Stock RG, Stone N. Biochemical outcomes after prostate brachytherapy with 5-year minimal follow-up: importance of patient selection and implant quality. Int J Radiat Oncol Biol Phys 2003; 57: 645-653.

11. Stock RG, Stone NN, Lo YC et al. Postimplant dosimetry for (125)I prostate implants: definitions and factors affecting outcome. Int J Radiat Oncol Biol Phys 2000; 48: 899-906.

12. Gregory KJ, Pattison JE, Bibbo G. Measurement uncertainty analysis of low-dose-rate prostate seed brachytherapy: post-implant dosimetry. Australas Phys Eng Sci Med 2015; 38: 71-81.
13. Alexander J, Weinberg V, Gottschalk AR et al. Pre-plan parameters predict post-implant D90 >/= 140 Gy for (125)I permanent prostate implants. J Contemp Brachytherapy 2014; 6: 143-153.

14. Ishiyama H, Satoh $\mathrm{T}$, Sekiguchi A et al. Comparison of three different techniques of low-dose-rate seed implantation for prostate cancer. J Contemp Brachytherapy 2015; 7: 3-9.

15. Wang Y, Nasser NJ, Borg J et al. Evaluation of the dosimetric impact of loss and displacement of seeds in prostate low-dose-rate brachytherapy. J Contemp Brachytherapy 2015; 7: 203-210.

16. Roach M 3rd, Hanks G, Thames H Jr et al. Defining biochemical failure following radiotherapy with or without hormonal therapy in men with clinically localized prostate cancer: recommendations of the RTOG-ASTRO Phoenix Consensus Conference. Int J Radiat Oncol Biol Phys 2006; 65: 965-974.

17. Stock RG, Stone NN, DeWyngaert JK et al. Prostate specific antigen findings and biopsy results following interactive ultrasound guided transperineal brachytherapy for early stage prostate carcinoma. Cancer 1996; 77: 2386-2392.

18. Sugawara A, Nakashima J, Kunieda E et al. Preimplant factors affecting prostate D90 after transperineal interstitial prostate brachytherapy with loose (125)I seeds. Keio J Med 2012; 61: 89-94.

19. Salembier C, Rijnders A, Henry A et al. Prospective multi-center dosimetry study of low-dose Iodine- 125 prostate brachytherapy performed after transurethral resection. J Contemp Brachytherapy 2013; 5: 63-69.

20. Nasser NJ, Wang Y, Borg J et al. Sector analysis of dosimetry of prostate cancer patients treated with low-dose-rate brachytherapy. Brachytherapy 2014; 13: 369-374.

21. Merrick GS, Butler WM, Grimm P et al. Permanent prostate brachytherapy extracapsular radiation dose distributions: analysis of a multi-institutional database. J Contemp Brachytherapy 2013; 5: 117-121.

22. Patil N, Crook J, Saibishkumar EP et al. The effect of obesity on rectal dosimetry after permanent prostate brachytherapy. Brachytherapy 2009; 8: 218-222.

23. Tiberi D, Gruszczynski N, Meissner A et al. Influence of body mass index and periprostatic fat on rectal dosimetry in permanent seed prostate brachytherapy. Radiat Oncol 2014; 9: 93.

24. Otón LF, Dolado MC, Núñez EJ et al. Effect of constipation on dosimetry after permanent seed brachytherapy for prostate cancer. J Contemp Brachytherapy 2015; 7: 247-251.

25. Lafata, KJ, Bushe H, Aronowitz JN. A simple technique for the generation of institution-specific nomograms for permanent prostate cancer brachytherapy. J Contemp Brachytherapy 2014; 6: 293-296. 